\title{
viewpoint
}

\section{The public option}

\author{
A possible change in US regulatory protocol for genetically modified organisms: compromised \\ or enhanced objectivity?
}

Jennifer Kuzma \& Zahra Meghani

G enetically modified organisms (GMOs) have been developed and used for many agricultural, pharmaceutical and industrial purposes. However, they remain controversial and have triggered intense, sometimes bitter, debate about the scientific, ethical, political and social issues they raise, including the inherent risks and benefits of biotechnology and its impact on the power relationship between producers and consumers. Furthermore, differing national standards for overseeing and regulating $\mathrm{GMOs}$ - and for the regulation and labelling of food products made from GMOs-have become a source of conflict, particularly between the USA and the EU, with trade relations between these two economic powers significantly affected.

This might be about to change: 10 days after taking office on 20 January 2009, US President Barack Obama issued an executive memo giving the director of the Office of Management and Budgetthe federal office in charge of reviewing regulations-100 days to prepare recommendations for a new executive order (EO) concerning federal regulatory review (EOP, 2009). The memo stipulated that the director's recommendations should include suggestions for encouraging public participation in agency regulatory processes; increasing the transparency of regulatory processes; reviewing distributional considerations, fairness and concern for future generations; and the role of the behavioural sciences in formulating regulatory policy (OMB, 2009).

Here, we examine whether these suggestions, particularly the one related to public participation, would compromise the objectivity of risk-based decision-making processes for GMOs and the products made from them. We also consider how the relations among stakeholders and between nations might change if there is substantive public participation in GMO regulatory review in the USA.

$\mathrm{T}$ he system that oversees and regulates the use of GMOs in the USA was first formally developed in the 1970s for laboratory processes and products. Initially, the National Institutes of Health Recombinant DNA Advisory Committee was charged with overseeing laboratory experiments that involved GMOs. As the technology matured and the first industrial and medical applications were developed, the Coordinated Framework for the Regulation of Biotechnology (CFRB) was established in 1986 to regulate the release of GMOs and their products into the environment (OSTP, 1986). The framework assumed that the risks associated with GMOs were the "same in kind" as those correlated with non-GM products (NRC, 2000) and focused on the product, not the process. Existing laws were deemed sufficient to cover the use of GM plants and microorganisms. The CFRB was and remains committed to a science-based decision-making process, which, in accordance with overall US federal regulatory policy, is empiricist and rooted in risk and cost-benefit analyses (EOP, 1993, as amended in 2002 and 2007).

The regulation and oversight of GMOs in the USA involves various agencies, primarily the US Food and Drug Administration (FDA), the US Environmental Protection Agency (EPA) and the US Department of Agriculture (USDA). For example, if GM plants contain engineered DNA sequences from viruses and bacteria that cause plant diseases, or if the plants themselves are plant pests, they fall under the regulation of the USDA within the Plant Pest Act. Conversely, GM plants engineered to contain pesticidal proteins-also know as 'plant incorporated protectants' -are regulated by the EPA under the Federal Insecticide, Fungicide and Rodenticide Act and the Federal Food Drug and Cosmetic Act (FFDCA). GM microorganisms are regulated by the EPA as "toxic chemicals" under the Toxic Substances Control Act, and GM or bioengineered foods are reviewed under the FFDCA by the FDA through a voluntary consultation mechanism. The CFRB did not specifically address the regulation of GM insects, trees, plant pharmaceuticals, fish or mammals, and there is still a lack of clarity about their oversight. Recently, the FDA proposed to oversee GM animals as "investigational new animal drugs" under the FFDCA (FDA, 2009).

\section{The executive memo from President Obama might, therefore, be the beginning of a seismic shift in the way risks from GMOs are assessed in the USA}

Experts from these federal agencies examine data and information submitted by sponsoring companies to decide whether the products are sufficiently safe to enter the market. Producers of GMOs aim to demonstrate that their products pose minimal risk-as defined by the law under which they fall. When the nature or degree of risk is uncertain, 
US regulatory agencies tend to favour the null hypothesis; namely, that there is no significant risk posed by the GMOs or their products when compared with similar products on the market. The US approach has therefore been described as a promotional approach toward the technology (Paarlberg, 2000).

\section{Increased public engagement, mandated by a new EO, could significantly change how the USA deals with GMOs and their products}

In addition, the agencies seek public input about risks and safety concerns through the US Federal Register (FR) notification process. Before promulgation, draft decisions and rules are published in the $F R$ and the public is invited to comment on them in a given time period. It is then at the discretion of the regulatory agencies to address public concerns by amending their reports or decisions (Kerwin, 2003). Other than the $F R$, the current system provides few opportunities for the public to substantively participate in decision making about GMOs (Thompson, 2007; Kuzma \& Besley, 2008).

$\mathrm{F}$ ederal agencies in charge of overseeing GMOs claim that they base their decision making primarily on "sound science" and objective risk assessment (OSTP, 1986; NRC, 2000); they deny that their assessments are shaped by normative considerations (de Melo-Martín \& Meghani, 2009). For example, the FDA refused to address normative concerns raised about food products derived from cloned animals on the grounds that it was "not charged with addressing non-science based concerns such as the moral, religious, or ethical issues associated with animal cloning for agricultural purposes, the economic impact of products being released in commerce, or other social issues unrelated to FDA's public health mission" (FDA, 2009). Non-governmental organizations, consumer groups and concerned citizens have therefore been forced to construct arguments that are grounded in "science-based" risk evaluations to ensure that regulatory agencies will enter into a dialogue with them (Thompson, 2007).
Regulatory decisions are made by federal agency experts in consultation with industry; some regulatory government experts might have worked for the industries they now regulate (Ferrara, 1998; Mattera, 2004). Transparency is also an issue for the oversight of GMOs in the USA. Product developers often claim that the information used for risk evaluation is confidential (NRC, 2000), therefore making it difficult for other stakeholders and citizens to access the studies that the agency takes into consideration as it assesses biotechnological products such as GMOs.

The oversight and regulation of GMOs in the USA differs in many respects from the approach taken by the EU, where regulatory decisions are supposed to be guided by a precautionary approach if the risks are uncertain and the burden is typically on developers to demonstrate that their product is safe. The EU's decision-making process is also attentive to social and ethical issues: "Respect for ethical principles recognized in a Member State is particularly important. Member States may take into consideration ethical aspects when GMOs are deliberately released or placed on the market as or in products" (EU, 2001). The EU emphasizes public consultation, asserting that it is, "necessary to ensure that the public is consulted by either the Commission or the Member States during the preparation of measures and that they are informed of the measures taken during the implementation of this Directive."

$\mathrm{F}$ ormer Presidential EOs in the USA strengthened and maintained a regulatory approach that is geared towards risk assessments informed by "sound science" and economic cost-benefit analyses. By contrast, the new FR notice asks for suggestions for encouraging public participation in regulatory review and to consider other elements such as distributional fairness. The executive memo from President Obama might, therefore, be the beginning of a seismic shift in the way risks from GMOs are assessed in the USA. If public participation became part of a new EO on regulatory protocol, the risk-based decision making of US regulatory agencies might shift from a risk assessment protocol wherein policy decisions are the purview of government and industry experts, to one where the public has a substantial say in deciding social, ethical, or political questions that arise during risk assessment.
Increased public engagement, mandated by a new EO, could significantly change how the USA deals with GMOs and their products. For example, it might lead to the labelling of products that contain GMOs; at present, GM products do not have to be labelled in the USA, although polling reveals that the majority supports mandatory labelling (Harris, 2004). This could also have international implications: one part of a lengthy World Trade Organization dispute from 1998 to 2004 over the EU's de facto moratorium on importing GM products from the USA (PIFB, 2005) involved the absence of a labelling policy in the USA, whereas the EU requires mandatory labelling above a threshold of $0.9 \%$ GM content.

\section{The idea that risk assessment can be an objective (that is, value-neutral) epistemic activity is not justified: all four stages of risk assessment have normative components}

However, it is still unclear what public engagement in the US regulatory review process could eventually mean. It is not obvious that the revised EO will mandate that regulatory agencies become responsive to public concerns such that new guidelines, policies and regulations are cognizant of them. We contend that this depends, at least partly, on the way that regulatory bodies conceive objectivity.

W hen faced with the task of assessing the potential risk of new products or technologies, US regulatory agencies presume that risk evaluations are objective: purely scientific endeavours that are denuded of normative considerations. In other words, they assume that there is a clear distinction between facts and values and that risk assessments are value neutral. This idea of risk assessment evolved in the second half of the twentieth century and is rooted in the finance and insurance industries. With the increasing use of nuclear power in the USA during the 1960s and 1970s, risk assessment was remodelled to evaluate the risks posed by hazardous industries.

In the 1980s, risk evaluation was again modified to analyse a range of hazards to human health and the environment, including cancer and ecosystem disruptions 
(Jasanoff, 2005). US regulatory agencies interpreted risk assessment as a heuristic device or a method for systematic analysis that was not a science but an art. However, this attitude changed after several lawsuits and a decision by the US Supreme Court in 1980 that "forced federal regulators to carry out some form of quantification in support of their health safety and environmental regulations" (Jasanoff, 2005). In 1983, the US National Research Council formally defined risk assessment as steps involving hazard identification, dose-response assessment, exposure assessment and risk characterization, and suggested that it remain conceptually distinct from risk management (NRC, 1983). This influential scientific organization defined risk assessment as a, "largely scientific component of regulatory decision making that should precede, and be separated from, value judgments that were considered appropriate only at the later stage of 'risk management'" (Jasanoff, 2005).

\section{Democracy rests on the idea that the public_-rather than industry—should decide on normative issues that have an impact on members of the polity}

The idea that risk assessment can be an objective - that is, value-neutral-epistemic activity is not justified: all four stages of risk assessment have normative components. Decisions have to be made that involve non-epistemic values and concerns during hazard identification, dose-response assessment, exposure assessment and risk characterization. For instance, because "it is impractical to study all possible relationships for all possible responses" (EPA, 2008), researchers make choices about the kind and level of adverse impacts they will study based on particular normative concerns.

The choice of questions, endpoints and methods in risk evaluation studies are normative decisions. The decision to include some populations, but not others, has ethical, social and political significance. For example, the industry's decision to not conduct long-term safety trials of GMOs using vulnerable populations-children, pregnant women, the immuno-compromised or the elderly-that would detect subtle effects such as allergenicity, hormonal imbalances or food intolerances (NRC, 2000) means more expedient and uncomplicated market entry for GMOs. Similarly, regulatory agencies require data on the ecological effects of GMOs on only a few target or non-target species (NRC, 2000). Although it is understandable and prudent to limit the number of species, their choice is nonetheless a value judgement. Also consider that the USDA reviews GM crops according to a qualitative prediction of how the biology of the host organisms and the engineered gene product will affect the phenotype of the GMOs, and the risk it might represent for humans or the environment. There are arguments for revising this approach. Local and specialized knowledge from "interested and affected" parties is important for good risk characterization (NRC, 1996); for instance, an experienced farmer might know better the type and timing of the pests that affect his or her fields than a regulator, even if that regulator is an entomologist.

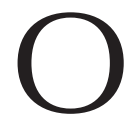
f course, stakeholders and citizens would bring their own biases to discussions about methodologies for evaluating risk and to the regulatory decision-making table. Some constituents might require that the impact of new GMOs on immuno-compromised patients be studied before the product is introduced to the market because they have a family member whose immune system is damaged. But normative concerns shape scientists' research decisions too. They might choose a particular research methodology because it is the one favoured by their peers and regulatory bodies, it is more easily conducted, or requires fewer resources. All in all, scientific experts', stakeholders' and citizens' perceptions of risks and benefits are influenced by non-epistemic concerns (Siegrist et al, 2007) and cultural world-views (Kahan et al, 2008).

Today, the interests of a select fewpredominantly industry-shape the regulatory review of GMOs in the USA. The new EO calling for comments on public participation in risk-based regulatory processes suggests that the current US administration is interested in making the process more democratic. This change would not necessarily be a threat to the integrity of risk-based decision making; tailored public participation in the risk evaluation process would not compromise the quality of the research, and risk evaluation will still have to meet the criteria of good research, including reproducibility and peer review (Morgan \& Henrion, 1990). The significant difference between the current protocol and one that encourages public involvement would be that the populace would have a say in deciding normative questions that arise during the process of risk evaluation. It would no longer be the case that decisions about study design and implementation that have ethical, social or political dimensions would be made by product developers, whether unilaterally or in conjunction with government agencies.

\section{...as regulatory review would be inclusive, and thus unbiased in a procedural sense, it would increase its legitimacy}

The participation of the public in the risk regulatory process that we espouse entails a commitment to "strong objectivity" (Harding, 1996, 1998). This term refers to the practice of scrutinizing epistemic activity, including risk assessment research, from the perspective of multiple stakeholders to identify the values that shape those endeavours and determine the normative concerns that ought to shape such activities. Implementation of strong objectivity by the FDA, EPA or USDA would reconfigure the process of risk assessment. The values that do and ought to shape the risk evaluation of GMOs, for instance, would be subject to rigorous public examination and debate.

Democracy rests on the idea that the public-rather than industry-should decide on normative issues that have an impact on members of the polity. If tailored public participation determines which normative concerns should guide the risk evaluation of biotechnologies, including GMOs released into the environment, it would make the process more democratic and pluralist. Moreover, as regulatory review would be inclusive, and thus unbiased in a procedural sense, it would increase its legitimacy. The drafting of a new EO concerning US regulatory review, especially in a highly contested area such as the regulation of GMOs, is a crucial opportunity to institutionalize substantial public participation in the regulatory process. 


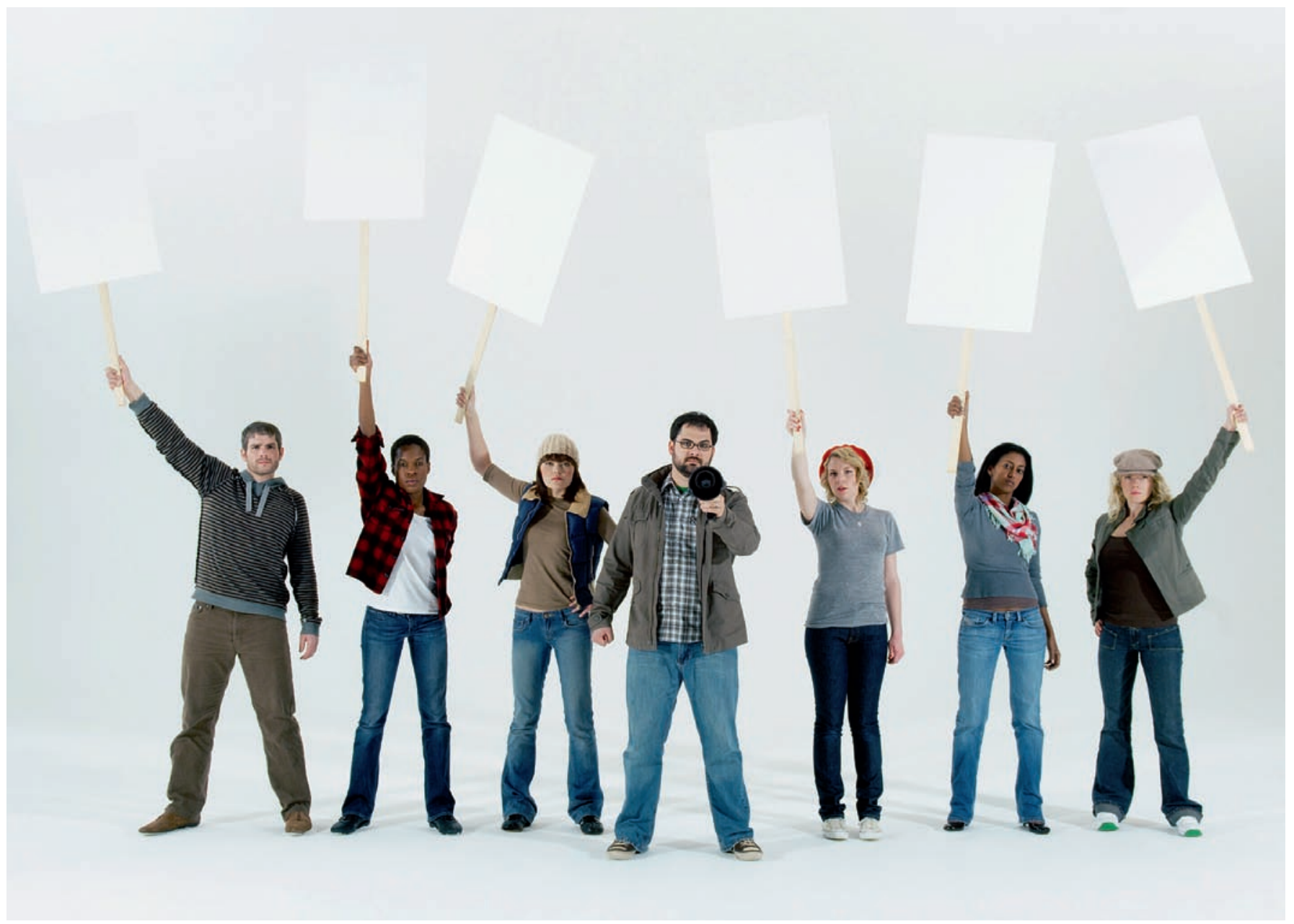

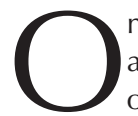
ne way to engage interested and affected parties in the early stages of the technology's development-before it yields the first tangible products and applications-is "Upstream Public Engagement" (UPE; Wildson \& Willis, 2004). By identifying risks and concerns early on, this approach could direct the development process and circumvent pitfalls such as public anger at having normative decisions about risk acceptability made by industry. However, the use of UPE in decision making concerning technological development and risk assessment has not been without criticism. Specifically, critics contend that UPE could be dominated by non-governmental organizations (NGOs) that do not represent the views of the average citizen; it could replace scientific facts and opinions for others that are "less based on scientific evidence than the previous one"; and there is no need for UPE because the current regulatory process ensures that any new product is "proven safe before it reaches the market" (Tait, 2009).

\section{...the strong objectivity approach requires that the public have access to relevant information about GMOs to enable them to make informed decisions}

Although all stakeholders in a democracy have an equal right to participate in decision-making processes, strategies to engage the public should be structured in a way that prevents discussions from being dominated by any particular constituency. There are methods to prevent debates being monopolized by particular stakeholders, and many successful citizen engagement exercises have taken place (Stilgoe \& Wilsdon, 2007). In the
USA, hundreds of citizens nationwide have participated in public forums and public engagement exercises about nanotechnology development and use. These have resulted in policy reports about nanotechnology directly authored by the citizen participants (Hamlett et al, 2008). Of course, much more needs to be done to ensure that public engagement cuts across social strata, including those of class, race and gender.

The second concern-that UPE will lead to decision making that is less scientific than the current process-deserves careful consideration. However, it presumes that the current decision-making process is value-neutral. We have already argued that it is not. Inevitably, decisions about technological development or risk assessment are influenced by ethical, social or political concerns. Lastly, the assumption that the current regulatory review process makes UPE unnecessary is not justified. As there is 
uncertainty about the risk posed by GMOs and other technologies, and as those risks will be borne by the public, it is crucial that the people have substantive say about which risks they find acceptable. The alternativegovernment experts, who make decisions in conjunction with industry experts-is paternalistic and undemocratic.

$\mathrm{O}$ f course, implementation of UPE is not easy. First, there is no consensus about when and how the public should be engaged or how the public's stance on particular normative questions should be integrated into regulatory decision making. Resource constraints and the specific goals of engagement will also determine the extent of public involvement (Rowe \& Frewer, 2004). Second, some natural scientists, unlike social scientists, might resist a democratic approach to regulatory review if they subscribe to the traditional idea of objectivity - that risk assessments can and should be value-neutral activities that ought to be conducted by scientific experts, without public interference. However, Gibbons (1999) argues that the changing nature of the relationship between science and society requires "contextualization" as well as engagement on the part of natural scientists with a wide variety of stakeholders. Tighter relationships among private, public and academic sectors in the conduct of science and development of technologies, such as GMOs, blur sector boundaries and call for a new social contract between science and society that requires science to be not only reliable, but also "socially robust" (Gibbons, 1999).

Another challenge to achieving wider public engagement in decision making is a lack of transparency. It is not unusual for developers and producers of GM products to argue that basic information about their products has to remain confidential (NRC, 2000; PIFB, 2006), otherwise they will be unable to recoup investments in research and development. However, the strong objectivity approach requires that the public have access to relevant information about GMOs to enable them to make informed decisions. It is probably not a coincidence that the new EO also calls for comments on increasing transparency.

As the cost of not engaging citizens in regulatory review is perhaps greater than that of doing so, it should be a practical incentive for regulatory agencies to change their review protocols. Several court challenges to USDA's environmental risk assessment process have been made in the past two years by NGOs. US Federal District Courts have ruled against the USDA in two cases on the grounds that the agency provided inadequate data to support its decision to allow deregulation of GM alfalfa and that it ignored evidence of environmental harm in field trials of GM bentgrass (McHugen \& Smyth, 2008). As a result, USDA was prompted to complete its first comprehensive environmental impact statement for GM crops (USDA, 2007).

The USDA has also been pushed to propose a reinterpretation of the Plant Pest Act and revisions to its regulations of GMOs (USDA, 2008). The revisions are complex and they are now being contested through the public comment process. Consumer groups argue that the new rules favour industry (CFS, 2009). After receiving thousands of comments, the agency twice extended the comment period and is now organizing public meetings. It makes little sense for regulatory bodies to make changes to their review protocol only in response to public pressure or to legal or political duress.

Instead, in the spirit of the new EO, if regulatory entities changed their review processes so that they engage the public early on, it would not only avoid costly legal challenges, but the regulatory protocol would meet the criteria for strong objectivity. Given that risk assessments are not value-neutral endeavours, and given that, in the end, it is the public that has to bear the brunt of any negative effects, this seems an ethical and prudent course of action.

\section{CONFLICT OF INTEREST}

The authors declare that they have no conflict of interest.

\section{REFERENCES}

CFS (2009) Re: Proposed Rule, APHIS Docket 2008-0023. June 29. Washington, DC, USA: The Center for Food Safety

de Melo-Martín I, Meghani Z (2009) The US Food and Drug Administration's evaluation of the safety of animal clones: a failure to recognize the normativity of risk assessment projects. Bull Sci Technol Soc 29: 9-17

EOP $(1993,2002,2007)$ Executive order 12866, as amended by EO 13258 of February 26, 2002 and EO 13422 of January 18, 2007. Regulatory planning and review. Fed Regist 58: $51735-51744$

EOP (2009) Memorandum for the heads of executive departments and agencies. Fed Regist 74: 5977
EPA (2008) Step 2-Dose-Response Assessment. http://www.epa.gov/risk/dose-response.htm

EU (2001) Directive 2001/18/EC of the European Parliament and of the Council of 12 March 2001 on the Deliberate Release into the Environment of Genetically Modified Organisms and Repealing Council Directive 90/220/EEC. Brussels, Belgium: European Union

FDA (2009) FDA's Response to Public Comment on the Animal Cloning Risk Assessment, Risk Management Plan, and Guidance for Industry. July 11. Bethesda, MD, USA: US Food and Drug Agency

Ferrara J (1998) Revolving doors: Monsanto and the regulators. Ecologist 28: 280-287

Gibbons M (1999) Science's new social contract with society. Nature 402: C81-C84

Hamlett P, Cobb MD, Guston DH (2008) National Citizens'Technology Forum: Nanotechnologies and human enhancement. CNS-ASU Report R08-0003. Tempe, AZ, USA: Center for Nanotechnology in Society, Arizona State University

Harding S (1996) Rethinking standpoint epistemology: what is 'strong objectivity?' In Keller EF, Longino $\mathrm{H}$ (ed), Feminism and Science, pp 235-248. Oxford, UK: Oxford University Press

Harding S (1998) Is Science Multicultural? Postcolonialism, Feminism, and Epistemologies. Indianapolis, IN, USA: Indiana University Press

Harris (2004) Genetically modified foods and crops: public still divided on benefits and risks. The Harris Poll Jul 2

Jasanoff S (2005) Designs on Nature: Science and Democracy in Europe and the United States. Princeton, NJ, USA: Princeton University Press

Kahan DM, Braman D, Slovic P, Gastil J, Cohen G (2008) Cultural cognition of the risks and benefits of nanotechnology. Nat Nanotechnol 4: 87-90

Kerwin CM (2003) Rulemaking: How Government Agencies Write Law and Make Policy. Washington, DC, USA: CQ

Kuzma J, Besley J (2008) Ethics of risk analysis and regulatory review: from bio- to nanotechnology. NanoEthics 2: 149-162

Mattera P (2004) USDA INC.: How Agribusiness has Hijacked Regulatory Policy at the US Department of Agriculture. Washington, DC, USA: Agribusiness Accountability Initiative and Corporate Research Project of Good Jobs First

McHugen A, Smyth S (2008) US regulatory system for genetically modified [genetically modified organisms (gmo), rDNA or transgenic] crop cultivars. Plant Biotechnol / 6: 2-12

Morgan G, Henrion M (1990) Uncertainty: A Guide to Dealing with Uncertainty in Quantitative Risk and Policy Analysis. Cambridge, UK: Cambridge University Press

NRC (1983) Risk Assessment in the Federal Government: Managing the Process. Washington, DC, USA: National Academies Press

NRC (1996) Understanding Risk. Washington, DC, USA: National Academies Press

NRC (2000) Genetically Modified Pest-Protected Plants: Science and Regulation. Washington, DC, USA: National Academies Press

OMB (2009) Federal Regulatory Review. Fed Regist 74: 8819 
OSTP (1986) Coordinated framework for the regulation of biotechnology. Fed Regist 51: 23302

Paarlberg RL (2000) Governing the GM crop revolution: policy choices for developing countries. In Food, Agriculture and the Environment Discussion Paper 33. Washington, DC, USA: International Food Policy Research Institute

PIFB (2005) US vs. EU: An Examination of the Trade Issues Surrounding Genetically Modified Food. Philadelphia, PA, USA: Pew Initiative on Food and Biotechnology

PIFB (2006) Agricultural Biotechnology Information Disclosure: Accommodating Conflicting Interests Within Public Access Norms. Philadelphia, PA, USA: Pew Initiative on Food and Biotechnology

Rowe G, Frewer LJ (2004) Evaluating publicparticipation exercises: a research agenda. $\mathrm{Sci}_{\mathrm{C}}$ Technol Human Values 29: 512-557

Siegrist M, Keller C, Kastenholz H, Frey S, Wiek A (2007) Laypeoples' and experts' perceptions of nanotechnology hazards. Risk Anal 27: 59-69
Stilgoe J, Wilsdon J (2007) Rules of engagement: democracy and dialogue in creating nanotechnology futures. In Allhoff F, Lin P, Moor J, Weckert J (eds), Nano-ethics: The Ethical and Social Implications of Nanotechnology, pp241-250. New York, NY, USA: Wiley Interscience

Tait J (2009) Upstream engagement and the governance of science. EMBO Rep 10: S18-S22

Thompson P (2007) Food Biotechnology in Ethical Perspective. Dordrecht, the Netherlands: Springer

USDA (2007) Introduction of Genetically Engineered Organisms. Draft Programmatic Environmental Impact Statement, July 2007. Washington, DC, USA: US Department of Agriculture

USDA (2008) Importation, interstate movement, and release into the environment of certain genetically engineered organisms: proposed rule. Fed Regist 73: 60008-60048

Wilsdon J, Willis R (2004) See-through Science. London, UK: Demos
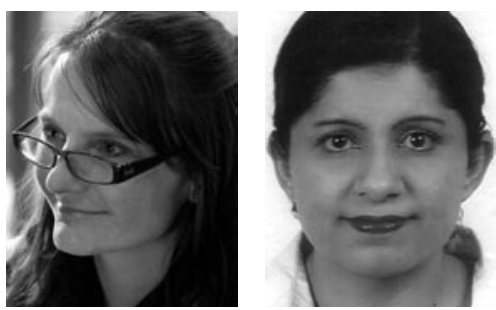

Jennifer Kuzma (left) is an associate professor of science, technology, and environmental policy at the Humphrey Institute of Public Affairs at the University of Minnesota, Minneapolis, USA.

E-mail:kuzma007@umn.edu

Zahra Meghani (right) is an assistant professor in the Department of Philosophy at the University of Rhode Island, Rhode Island, USA.

E-mail:meghaniz@mail.uri.edu

Published online 13 November 2009

doi:10.1038/embor.2009.250 